\title{
Mental health diagnosis and occupational functioning in National Guard/Reserve veterans returning from Iraq
}

\author{
Christopher R. Erbes, PhD; ${ }^{1-2^{*}}$ Matthew E. Kaler, PhD; ${ }^{1}$ Tamara Schult, MPH; ${ }^{1,3}$ Melissa A. Polusny, PhD; ${ }^{1-2,4}$ \\ Paul A. Arbisi, $\mathbf{P h D}^{1-2,5}$ \\ ${ }^{1}$ Minneapolis Department of Veterans Affairs (VA) Health Care System, Minneapolis, MN; ${ }^{2}$ Department of Psychiatry, \\ University of Minnesota Medical School, Minneapolis, MN; ${ }^{3}$ Departments of Environmental Health Sciences and \\ Health Policy and Management, University of Minnesota School of Public Health, Minneapolis, MN; ${ }^{4}$ Center for \\ Chronic Disease Outcomes Research, Minneapolis VA Health Care System, Minneapolis, MN; ${ }^{5}$ Department of \\ Psychology, University of Minnesota, Minneapolis, $M N$
}

\begin{abstract}
Occupational functioning represents both an important outcome for military servicemembers returning from Operation Iraqi Freedom (OIF) and Operation Enduring Freedom and a predictor for long-term mental health functioning. We investigated the role of mental health diagnoses, determined by structured clinical interviews, on occupational functioning in a group of 262 National Guard/Reserve servicemembers within 1 year of returning from a 16-month OIF combat deployment. We assessed occupational functioning at the time of diagnostic interviews and 1 year later. We hypothesized that servicemembers with diagnoses of posttraumatic stress disorder (PTSD), depression, and/or alcohol abuse or dependence would exhibit lower rates of employment at both time points and lower rates of reported work and/or school role functioning. Servicemembers with a diagnosis of PTSD $(5 \%, n=13)$, subthreshold PTSD $(6 \%, n=15)$, a major depressive disorder $(11 \%, n=29)$, or alcohol abuse or dependence $(11 \%, n=28)$ did not differ on employment status from servicemembers without a diagnosis at either time point. However, those with a diagnosis of PTSD, depression, and/or alcohol abuse or dependence reported lower levels of work role functioning. In addition, servicemembers with a diagnosis of PTSD reported greater rates of deterioration in work role functioning over time.
\end{abstract}

Key words: alcohol abuse or dependence, combat deployment, comorbidity, depression, employment, mental health, National Guard, occupational functioning, posttraumatic stress disorder, work role functioning.

\section{INTRODUCTION}

A successful transition back into civilian life for returning veterans following combat deployment is a vital concern for the United States and the Department of Veterans Affairs (VA). Our newest generation of combat veterans returning from Iraq (Operation Iraqi Freedom [OIF]) and Afghanistan (Operation Enduring Freedom

\footnotetext{
Abbreviations: $\mathrm{AD}=$ Active Duty, AUDIT $=$ Alcohol Use Disorders Identification Test, BDI-II = Beck Depression InventorySecond Edition, CAPS = Clinician-Administered Posttraumatic Stress Disorder Scale, DRRI = Deployment Risk and Resilience Inventory, $\mathrm{MDD}=$ major depressive disorder, NGR = National Guard/Reserve, NOS = not otherwise specified, OEF = Operation Enduring Freedom, OIF = Operation Iraqi Freedom, PCL$\mathrm{M}=$ Posttraumatic Stress Disorder Checklist-Military Version, PTSD = posttraumatic stress disorder, RINGS = Readiness and Resilience in National Guard Soldiers, SAS-SR = Social Adjustment Scale-Self-Report, SCID = Structured Clinical Interview for the Diagnostic and Statistical Manual of Mental Disorders-Fourth Edition, T1 = time point 1, T2 = time point 2, VA = Department of Veterans Affairs.

*Address all correspondence to Christopher R. Erbes, PhD; Minneapolis VA Health Care System (116A6), One Veterans Drive, Minneapolis, MN 55417; 612-725-2000, ext 2125; fax: 612-727-5633. Email: christopher.erbes@va.gov DOI:10.1682/JRRD.2010.11.0212
} 
[OEF]) are faced with reintegrating into potentially disrupted family, social, and occupational roles; this may be even more difficult for National Guard/Reserve (NGR) veterans. Civilian reintegration can also be especially difficult for veterans experiencing mental health impairments (i.e., posttraumatic stress disorder [PTSD], depression, and alcohol or drug use disorders). We examined the role of mental health impairments on employment status and work role functioning in a cohort of NGR servicemembers in the first year following return from OIF combat deployment.

Military personnel returning from OIF/OEF are at increased risk for a range of mental health problems, including PTSD, depression, and alcohol abuse or dependence [1-3]. This risk appears to be greater for NGR veterans than regular Active Duty (AD) veterans [3-5]. Milliken et al. found that rates of PTSD and depressive symptoms more than doubled among NGR servicemembers within 6 months of their initial return from deployment and that this rate of increase substantially exceeded the rate of increase in regular AD servicemembers [5]. In a study examining trends and risk factors for mental health diagnoses among 289,328 OIF/OEF veterans entering VA healthcare from 2002 to 2008, Seal et al. found higher rates for PTSD, depression, and all other mental health diagnoses in NGR veterans seeking care in the VA compared with AD veterans [6]. Seal et al. also found that rates of mental health diagnosis increased over time following return from deployment. Thus, unfortunately, problems continue to develop for veterans in the months and years after returning from OIF.

Explanations for the differences between NGR and AD military personnel in mental health functioning include both deployment-related and postdeployment stressors that apply particularly to NGR servicemembers. Compared with AD military personnel, NGR servicemembers or "civilian soldiers" are more likely to have family and occupational circumstances that are not wellsuited for the prolonged absence of a combat deployment. For example, most NGR personnel have civilian jobs and careers that can be disrupted by a yearlong absence. Families may be both less accustomed to and less supported during these absences. In contrast with AD military culture, NGR servicemembers and families may not be integrated into military communities that are understanding and supportive of combat deployments. Thus, NGR servicemembers may face unique reintegration challenges as they move from warfighter to civilian roles, and occupational challenges may represent one key aspect of those challenges [7-8].

The mental health challenges confronting returning servicemembers, and NGR veterans in particular, may have negative implications for occupational functioning. Psychiatric disorders such as PTSD and depression have been associated with impaired occupational functioning in veterans from other conflicts, primarily in Vietnam war veterans. More than 20 years after the end of the Vietnam war, Savoca and Rosenheck found that a lifetime diagnosis of PTSD was associated with a nearly 50 percent lower probability of current employment in Vietnam war veterans [9]. In addition, effects on employment rates were nearly as large for major depressive disorders (MDDs) as well as anxiety disorders. Substance abuse also had a significant, but smaller, negative effect on probability of employment. PTSD and depression were associated with large decreases in hourly wage rates: 16 and 45 percent, respectively. Similarly, in a sample of 325 veterans with PTSD receiving treatment, Smith et al. found that Vietnam war veterans with more severe PTSD symptoms were more likely to work part-time or not at all compared with veterans with less severe symptoms [10]. A weak association also existed between more severe symptoms and having a lower-level position (i.e., sales or clerical position) among those veterans who were working.

Numerous studies in the civilian population have further documented deleterious effects of mental health diagnoses on the broader construct of occupational functioning, including workplace performance and productivity. In general, the presence of psychiatric disorders and comorbid conditions has an enormous effect on workplace performance and productivity. Accumulating evidence indicates that psychiatric disorders impair rather than completely incapacitate workers' functional ability [11-14]. Depression was the largest single predictor of absenteeism and reduced work performance among any condition examined in two recent worker studies. Further, the effects were exacerbated by the presence of comorbidities such as chronic pain, anxiety disorders, and fatigue-sleep disturbances [14-15].

In spite of the attention on the prevalence of mental health concerns among returning OIF/OEF veterans, the likely effect of mental health problems on occupational functioning, and the importance of occupational functioning on current and future well-being, we found a lack of systematic investigation into the work role functioning of returning veterans and the effect of mental health on that functioning. This article represents an initial investigation 
in this area. We assessed mental health diagnoses and occupational functioning in a group of NGR servicemembers about 6 months following their return from a combat deployment to OIF and assessed occupational functioning again 1 year later. We evaluated occupational functioning by both employment status (i.e., employed or in school vs unemployed) and self-reported work role functioning. The study design allowed us to examine the role of mental health diagnosis in predicting occupational functioning initially following return from deployment, 1 year later, and as functioning changed over time. We hypothesized that mental health diagnoses, including PTSD, subthreshold PTSD, MDD, and alcohol abuse or dependence, would be associated with lower rates of current employment and lower levels of current work role functioning. Additionally, we hypothesized that mental health diagnoses would predict deterioration in employment status and role functioning over time.

\section{METHODS}

\section{Participants}

We gathered data for this report as part of the Readiness and Resilience in National Guard Soldiers (RINGS) Cohort Study, a prospective, longitudinal study of risk and protective factors associated with postdeployment functioning (see Polusny et al. [16] for details). We drew participants from a group of 355 Army NGR servicemembers deployed to OIF between March 2006 and July 2007 who were enrolled in the RINGS Cohort Study and who had completed structured clinical diagnostic interviews within 1 year of their return from a combat deployment to OIF [17]. Of the 355 participants who took part in the diagnostic interviews, 262 also provided information on their occupational functioning at that time (time point 1 [T1]) and 1 year later in a follow-up mailed survey (time point 2 [T2]). These 262 participants made up the sample we used for the present analyses.

Table 1 provides participant demographics. The majority of participants was male $(87.8 \%)$, Caucasian (93.5\%), and enlisted rank (85.9\%). Age was $30.47 \pm$ 8.73 (mean \pm standard deviation). About half were married (53.8\%). The sample represented a range of military occupational specialties categorized as follows: Combat Arms (45.4\%), Combat Support (14.1\%), and Combat Service Support (39.7\%). A comparison of the 355 participants who had completed diagnostic interviews with the subset included in the present analyses (those with complete $\mathrm{T} 1$ and $\mathrm{T} 2$ data) found that those with complete data did not differ from those T1 respondents without

Table 1.

Demographics and time point 1 (T1) self-report results.

\begin{tabular}{|c|c|c|}
\hline Demographic & $\begin{array}{l}\text { Diagnostic Interview } \\
\quad(n=355)\end{array}$ & $\begin{array}{c}\text { Diagnostic Interview and T1/T2 } \\
\text { Occupational Data }(n=262)\end{array}$ \\
\hline Age at T1 (mean \pm SD) & $31.60 \pm 8.60$ & $30.47 \pm 8.73$ \\
\hline White ( $n, \%)$ & $331(93.2)$ & $245(93.5)$ \\
\hline Male $(n, \%)$ & $310(87.3)$ & $230(87.8)$ \\
\hline Married $(n, \%)$ & 175 (49.3) & $141(53.8)$ \\
\hline \multicolumn{3}{|l|}{ Highest Education Level (n, \%) } \\
\hline High School or GED & $42(11.8)$ & $30(11.5)$ \\
\hline 4-year Degree & $71(20.0)$ & 59 (22.5) \\
\hline Graduate Degree & $20(5.6)$ & $18(6.9)$ \\
\hline Enlisted Rank (n, \%) & $313(88.2)$ & 225 (85.9) \\
\hline \multicolumn{3}{|l|}{ Role ( $n, \%)$} \\
\hline Combat Arms & $166(46.8)$ & $119(45.4)$ \\
\hline Combat Support & $51(14.4)$ & $37(14.1)$ \\
\hline Service Support & $134(37.7)$ & 104 (39.7) \\
\hline DRRI Combat Experiences Scale score (mean \pm SD) & $28.78 \pm 8.28$ & $28.15 \pm 7.40$ \\
\hline PCL-M score (mean \pm SD) & $35.5 \pm 13.64$ & $34.79 \pm 12.79$ \\
\hline BDI-II score (mean \pm SD) & $9.78 \pm 7.95$ & $9.65 \pm 7.92$ \\
\hline AUDIT score (mean \pm SD) & $7.07 \pm 5.92$ & $6.69 \pm 5.93$ \\
\hline
\end{tabular}

AUDIT = Alcohol Use Disorders Identification Test, BDI-II = Beck Depression Inventory-Second Edition, DRRI = Deployment Risk and Resilience Inventory, GED = General Educational Development test, PCL-M = Posttraumatic Stress Disorder Checklist-Military Version, SD = standard deviation, T2 = time point 2. 
complete data on age; race; sex; marital status; highest level of education completed; military rank; role in deployment; combat exposure; or baseline measures of PTSD, depression, and alcohol abuse or dependence.

\section{Procedures}

Data for the present report included clinical diagnoses and self-report measures of postdeployment mental health symptoms (PTSD, depression, and alcohol use disorders), combat exposure (used to check for possible selection bias in respondents), and occupational functioning. Details of the survey and clinical interview procedures are available elsewhere [16-17].

\section{Measures}

Posttraumatic Stress Disorder Checklist-Military Version

The Posttraumatic Stress Disorder Checklist-Military Version (PCL-M) is a 17-item self-report scale that assesses each of the symptoms of PTSD, using a Likerttype response format (from 1 to 5), as they relate to a participant's military experiences [18]. The PCL-M is widely used in military population studies and has demonstrated excellent internal consistency and test-retest reliability. It correlates highly with other measures of PTSD [19].

\section{Beck Depression Inventory-Second Edition}

The Beck Depression Inventory-Second Edition (BDI-II) is a 21-item self-report questionnaire that assesses the presence and severity of symptoms of depression [20]. The BDI-II is one of the most widely used scales of depressive symptoms and has established internal consistency, reliability, and validity [21].

\section{Alcohol Use Disorders Identification Test}

The Alcohol Use Disorders Identification Test (AUDIT) is a 10-item self-report measure of alcohol use frequency, quantity, and associated problems [22]. It has been shown to be reliable and valid in a variety of populations.

\section{Social Adjustment Scale-Self-Report}

The Social Adjustment Scale-Self-Report (SAS-SR) is a 54-item self-report questionnaire that assesses role functioning in multiple domains, including work, social and leisure activities, and family relationships [23]. The present analyses used the work/school role functioning subscale, which measures overall role functioning, including performance, attendance, and confidence, in the areas of work and school over the past 2 weeks. The SAS-SR has demonstrated high internal consistency and test-retest reliability.

\section{Employment Status}

In addition to role functioning, we assessed employment status with a single item asked at both $\mathrm{T} 1$ and $\mathrm{T} 2$ : "Are you currently in a paid job, in school, or neither?" We coded responses as "unemployed" for those whose answers indicated that they were not working or enrolled as a student.

\section{Deployment Risk and Resilience Inventory Combat Experiences Scale}

We used a modified version of the 15-item Combat Experiences Scale of the Deployment Risk and Resilience Inventory (DRRI) [24] to characterize types and level of combat experiences of participants. While the original DRRI Combat Experiences Scale used a "yes/no" response format, this survey used a Likert-type rating of the frequency of each combat experience, where $1=$ never and 5 = daily or almost daily. Internal consistency for this version of the DRRI was 0.84 in the present sample.

\section{Clinician Administered Posttraumatic Stress Disorder Scale}

We determined the diagnosis of PTSD using the Clinician-Administered Posttraumatic Stress Disorder Scale (CAPS) [25], which is considered the gold standard diagnostic interview for PTSD. The CAPS has excellent reliability and yields high internal consistency, interrater reliability, and test-retest reliability. The CAPS has also demonstrated excellent convergent and discriminant validity, diagnostic utility, and sensitivity to clinical change [26]. As reported in Kehle et al., all clinical interviews were recorded and a subset of 10 percent was rated independently to examine interrater reliability [17]. Reliability of symptom ratings on the CAPS, as measured by the two-way random effects intraclass correlation coefficient, was 0.83, and interviewers and independent observers concurred on all diagnoses. In addition to identifying PTSD, we also used the CAPS to diagnose subthreshhold PTSD (i.e., the presence of significant symptoms of PTSD that were related to impairment but did not meet full criteria for PTSD). Following Stein et al., subthreshhold PTSD was diagnosed if a traumatic 
event was experienced; at least one re-experiencing symptom, one avoidance symptom, and one hyperarousal symptom were reported; and the clinician rated moderate or greater overall impairment for the participant [27].

\section{Structured Clinical Interview for the Diagnostic and Statistical Manual of Mental Disorders-Fourth Edition}

We used the Structured Clinical Interview for the (Diagnostic and Statistical Manual of Mental DisordersFourth Edition, SCID) (non-patient edition, research version [28]), which assesses each criteria for mental health diagnoses from the Diagnostic and Statistical Manual of Mental Disorders-Fourth Edition, to assess additional psychiatric diagnoses. We administered the following modules of the SCID: overview, mood episodes, psychotic disorders, mood disorders, substance use disorders, anxiety disorders (with exception of PTSD questions), and somatoform disorders. Interrater reliability for the subset of 10 percent of diagnostic interviews that was independently rated was moderate to good, with kappas for individual diagnoses ranging from 0.56 to 1.00 and an overall interrater reliability for the SCID of 0.67 [17].

\section{RESULTS}

\section{Descriptive Analyses}

Scores on the SAS-SR work role functioning scale were approximately normally distributed at both time points, although they were slightly positively skewed and more kurtotic at T2 (T1: $1.62 \pm 0.47$; T2: $1.66 \pm 0.58)$. In the original sample of 355 participants, 23 (6.5\%) were diagnosed with PTSD, 42 (11.8\%) with MDD, and 45 (12.7\%) with alcohol abuse or dependence. Considering all diagnoses, 133 (37.5\%) had a current diagnosis of some kind. We found an additional 22 (6.2\%) participants to have subthreshold PTSD (as described earlier). In the present sample, 5.0 percent of participants experienced PTSD $(n=13), 5.7$ percent experienced subthreshold PTSD $(n=15), 11.1$ percent experienced MDD $(n=$ 29), 10.7 percent experienced alcohol abuse or dependence $(n=28)$, and 34.4 percent $(n=90)$ had any disorder. Similar to the original sample [17], comorbidity was common. Among those diagnosed with PTSD, 84.6 percent had one or more comorbid conditions (including 69.2\% with MDD and 23.1\% with alcohol use disorders). Among those with subthreshold PTSD, 60 percent had one or more other conditions (33\% with MDD and 27\% with an alcohol use disorder). Similarly, 62.1 percent of those with MDD had comorbid conditions (31.0\% with PTSD and 20.7\% with alcohol use disorders), and 46.4 percent of those with alcohol use disorders had comorbid conditions (10.7\% with PTSD and $21.4 \%$ with MDD). Note that some participants met criteria for a range of other diagnoses, including an anxiety disorder not otherwise specified (NOS) without PTSD symptoms $(n=15)$, dysthymia $(n=5)$, a depressive disorder NOS $(n=4)$, and drug abuse or dependence $(n=3)$, but these diagnoses were not present in sufficient numbers to include in the present analyses. Rates of diagnosis were not statistically different between those participants included in the present study and those who did not provide complete occupational data at both time points. Scores on the DRRI Combat Experiences Scale indicated a moderate amount of combat exposure overall, with 80 percent reporting four or more combat experiences, such as receiving hostile or incoming fire (94\%), going on combat missions or patrols (89\%), witnessing an ally being seriously wounded or killed (40\%), and firing a weapon at the enemy (27\%).

At T1, 45 (17.2\%) participants reported being unemployed and not in school, whereas 23 (8.8\%) reported unemployment at T2. Among participants, 33 (12.6\%) reported a change from unemployment to either paid work or full-time school between $\mathrm{T} 1$ and $\mathrm{T} 2$, while $11(4.2 \%)$ reported a transition from either working or full-time school to unemployment. The remaining 218 participants reported no change in status between time points.

\section{Employment Status and Diagnosis}

We used chi-square tests of proportion to examine whether diagnostic status predicted employment status. Specifically, we tested whether having any diagnosis, current PTSD diagnosis, current subthreshold PTSD diagnosis, current MDD diagnosis, or current alcohol use disorder diagnosis were related to employment status (employed vs unemployed) at both time points and also whether they were related to a change in employment (as summarized earlier). We set up groups comparing those with the target diagnoses with those with no diagnosis $(n=$ 170). Table 2 displays the results. Those with PTSD, subthreshold PTSD, MDD, and alcohol use disorders did not differ significantly from those without any disorders in terms of employment status at $\mathrm{T} 1\left(\chi^{2}=0.04,0.18,0.16\right.$, 
Table 2.

Work status and change in work status by diagnostic group.

\begin{tabular}{|c|c|c|c|c|c|c|c|c|c|c|}
\hline \multirow[b]{2}{*}{$\begin{array}{l}\text { Diagnostic } \\
\text { Group }\end{array}$} & \multicolumn{3}{|c|}{ T1 Work Status } & \multicolumn{3}{|c|}{ T2 Work Status } & \multicolumn{4}{|c|}{ T1 to T2 Change } \\
\hline & $\begin{array}{c}\text { Unemployed } \\
n(\%)\end{array}$ & $\begin{array}{c}\text { Employed } \\
n(\%)\end{array}$ & $\chi^{2}(1)$ & $\begin{array}{c}\text { Unemployed } \\
n(\%)\end{array}$ & $\begin{array}{c}\text { Employed } \\
n(\%)\end{array}$ & $\chi^{2}(1)$ & $\begin{array}{c}\text { Gain } \\
n(\%)\end{array}$ & $\begin{array}{c}\text { No Change } \\
n(\%)\end{array}$ & $\begin{array}{c}\text { Loss } \\
n(\%)\end{array}$ & $\chi^{2}(2)$ \\
\hline Any Diagnosis & $15(17)$ & $73(83)$ & 0.02 & $8(9)$ & $77(91)$ & 0.02 & $10(12)$ & $71(85)$ & $3(4)$ & 0.43 \\
\hline Subthresold PTSD* & $2(13)$ & $13(87)$ & 0.18 & $0(0)$ & $14(100)$ & 1.36 & $2(14)$ & $12(86)$ & $0(0)$ & 0.71 \\
\hline MDD & $6(21)$ & $23(79)$ & 0.16 & $3(11)$ & 24 (89) & 0.13 & $3(11)$ & $24(89)$ & $0(0)$ & 1.59 \\
\hline ETOH & $6(21)$ & $22(79)$ & 0.23 & $1(4)$ & $26(96)$ & 0.84 & $6(22)$ & $20(74)$ & $1(4)$ & 1.30 \\
\hline
\end{tabular}

*Anxiety disorder not otherwise specified with PTSD symptoms.

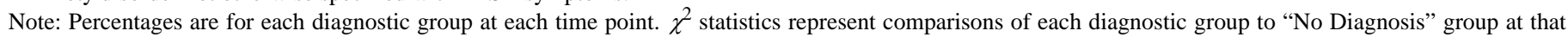
time point.

ETOH $=$ alcohol abuse/dependence, $\mathrm{MDD}=$ major depressive disorder, $\mathrm{PTSD}=$ posttraumatic stress disorder, $\mathrm{T} 1=$ time point 1 , T2 $=$ time point 2 .

and 0.23 , respectively, all nonsignificant) or T2 $\left(\chi^{2}=\right.$ $0.59,1.36,0.13$, and 0.84 , respectively, all nonsignificant), or in terms of change in occupational status $\left(\chi^{2}=0.56\right.$, $0.71,1.59$, and 1.30 , respectively, all nonsignificant).

\section{Work Role Functioning and Diagnosis}

Table 3 summarizes findings from three multiple regression analyses. The first test examined diagnostic status for PTSD, subthreshold PTSD, MDD, and alcohol use disorders as predictors of T1 SAS-SR work role functioning. The second test examined the same predictors for T2 SAS-SR work role functioning. The third and final test examined the diagnoses as predictors of change in SAS-SR work role functioning scores (with increasing scores indicating improving role functioning). Note that dichotomous variables entered into the regression analyses shown in Table 3 contrasted individuals with the target diagnosis with all other individuals in the sample. This was necessary to allow individuals with varying diagnoses to be examined in the analysis. While diagnostic status is a very important indicator, it can neglect information regarding subthreshold symptoms and severity of symptoms. Therefore, Table $\mathbf{4}$ summarizes findings from three analogous regression analyses using continuous symptom measures (i.e., PCL-M, BDI-II, and AUDIT) as predictors instead of diagnostic statuses.

Table 3 shows that diagnoses accounted for approximately 8 percent of the variance in work role functioning at T1, and MDD and alcohol-related diagnoses each emerged as significant independent predictors of reported decrements in work role functioning (alcohol-related diagnoses were the most powerfully predictive of the three). On the other hand, subthreshold PTSD was significantly predictive of improvement in work role functioning (albeit weakly). At T2, diagnoses accounted for 11 percent of the variance, and PTSD, MDD, and alcohol-related diagnoses were significantly and uniquely predictive of work role functioning. Finally, when entering diagnostic variables as well as work role functioning scores at T1 (to control for concurrent relations), the full model predicted 27 percent of the variance in work role functioning at T2; however, only PTSD emerged as a significant and unique predictor of T2 work role functioning (controlling for T1 work role functioning). Thus, a PTSD diagnosis was uniquely associated with decrements in work role functioning over time.

Using continuous measures of psychological symptoms as predictors, symptom measures accounted for 29 percent of the variance in work role functioning at $\mathrm{T} 1$. The BDI-II total score emerged as the only uniquely significant predictor in the model. At T2, symptoms accounted for 21 percent of the variance in work role functioning and, again, participants' BDI-II total scores were the sole uniquely significant predictor in the regression equation. Finally, controlling for the relations between the symptom measures and the SAS-SR at T1 (to index their relations with between time-point change on the SAS-SR), the full model accounted for 28 percent of the variance in work role functioning at T2. Both SASSR at T1 and the BDI-II emerged as unique and strong predictors of SAS-SR scores at T2.

Because co-occurrence among diagnoses (i.e., comorbidity) was common within the sample and comorbidity can have an effect on outcomes and functioning [29], we also conducted the regression analyses described earlier with an additional stepwise inclusion of interaction terms. Specifically, we tested whether interactions between pairs of each of the diagnoses (e.g., PTSD diagnostic status by MDD diagnostic status) were significant predictors of work 
Table 3.

Prediction of Social Adjustment Scale-Self-Report (SAS-SR) work role functioning (dependent variable) by time point 1 (T1) diagnostic status (independent variable).

\begin{tabular}{|c|c|c|c|c|c|c|}
\hline Diagnostic Status & $B$ & SE $B$ & $95 \% \mathrm{CI}$ & $B$ & $R^{2}$ & $r_{\text {pb }}$ \\
\hline$\overline{\mathrm{T} 1}$ & & & & & $0.08^{*}$ & \\
\hline PTSD & -0.06 & 0.15 & $-0.35,0.23$ & -0.03 & & 0.07 \\
\hline Subthreshold PTSD & -0.27 & 0.13 & $-0.52,-0.01$ & $-0.14^{\dagger}$ & & -0.09 \\
\hline MDD & 0.23 & 0.11 & $-0.02,0.45$ & $0.16^{\dagger}$ & & $0.16^{\dagger}$ \\
\hline ETOH & 0.30 & 0.10 & $-0.10,0.49$ & $0.20^{*}$ & & $0.20^{\ddagger}$ \\
\hline $\mathrm{T} 2$ & & & & & $0.11^{*}$ & \\
\hline PTSD & 0.40 & 0.18 & $0.04,0.76$ & $0.15^{\dagger}$ & & $0.23^{*}$ \\
\hline Subthreshold PTSD & 0.02 & 0.15 & $-0.27,0.32$ & 0.01 & & 0.05 \\
\hline MDD & 0.28 & 0.11 & $0.03,0.53$ & $0.15^{\dagger}$ & & $0.25^{*}$ \\
\hline ETOH & 0.34 & 0.15 & $0.12,0.56$ & $0.18^{\ddagger}$ & & $0.21^{\ddagger}$ \\
\hline $\mathrm{T} 2$ & & & & & $0.27^{*}$ & \\
\hline SAS-SR (T1) & 0.51 & 0.08 & $0.36,0.66$ & $0.42^{*}$ & & $0.45^{*}$ \\
\hline PTSD & 0.47 & 0.17 & $0.14,0.81$ & $0.19^{\ddagger}$ & & $0.23^{*}$ \\
\hline Subthreshold PTSD & 0.07 & 0.14 & $-0.21,0.36$ & 0.03 & & 0.05 \\
\hline MDD & 0.09 & 0.12 & $-0.15,0.33$ & 0.05 & & $0.25^{*}$ \\
\hline ETOH & 0.19 & 0.11 & $-0.03,0.41$ & 0.10 & & $0.21^{\ddagger}$ \\
\hline
\end{tabular}

${ }^{*} p<0.001$.

${ }^{\dagger} p<0.05$.

${ }^{\ddagger} p<0.01$.

$\mathrm{CI}=$ confidence interval, $\mathrm{ETOH}=$ alcohol abuse or dependence, $\mathrm{MDD}=$ major despressive disorder, $\mathrm{PTSD}=$ posttraumatic stress disorder, $r_{\mathrm{pb}}=$ point-biserial correlation, $\mathrm{SE}=$ standard error, T2 = time point 2.

Table 4.

Prediction of Social Adjustment Scale-Self-Report (SAS-SR) work role functioning (dependent variable) by time point 1 (T1) symptom severity (independent variable).

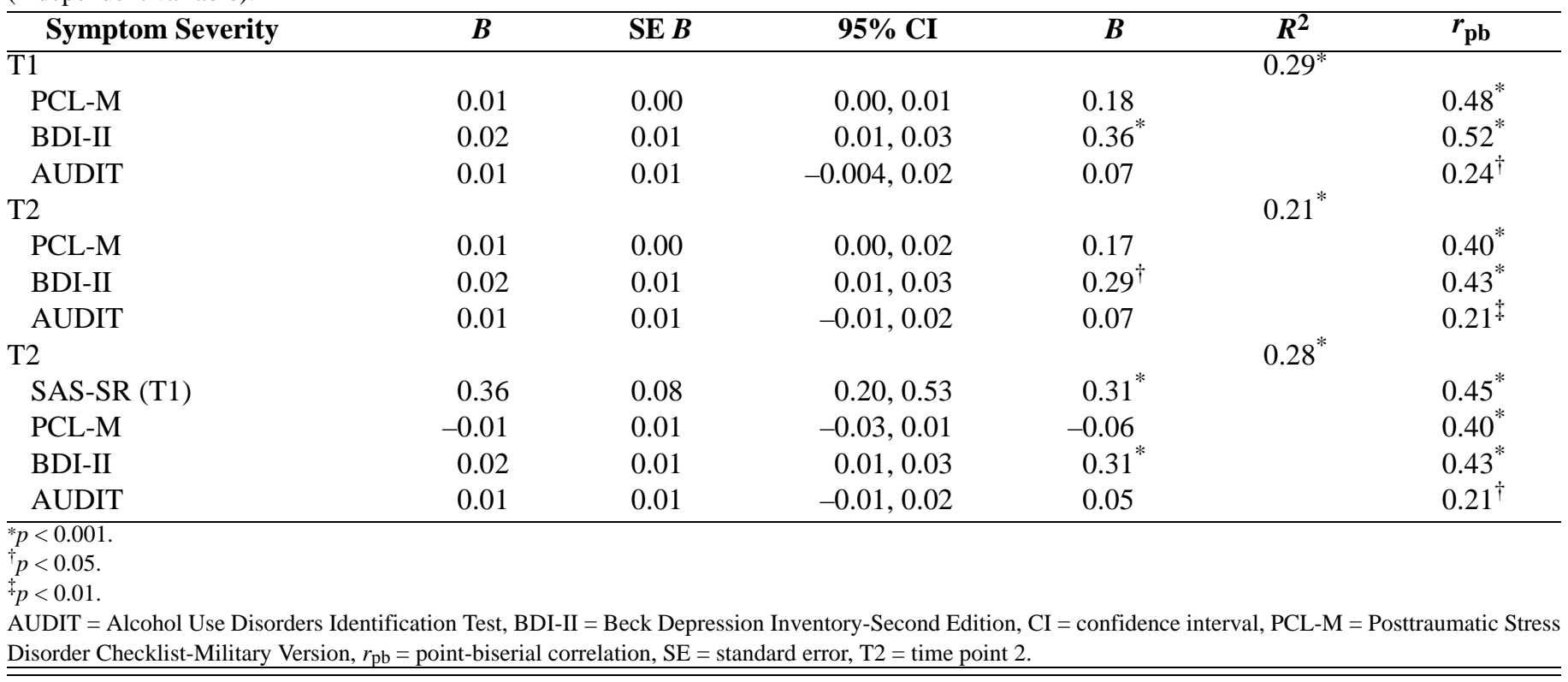

role functioning at either time point or at T2, controlling for work role functioning at T1. We also tested whether interactions between pairs of the continuous symptom mea- sures (e.g., PCL-M by BDI-II scores) were significant predictors in analogous regression models. None of the statistics indexing change in $R^{2}$ from step 1 (including only 
first-order effects) to step 2 (adding interaction effects) were significant. In fact, the addition of interaction terms explained no more than 1.8 percent of additional variance in any of the independent variables. Thus, singular interaction terms were not interpreted.

\section{DISCUSSION}

These results suggest that, as one might expect, NGR servicemembers with psychiatric diagnoses may struggle more with successful occupational functioning upon their return from a combat deployment. Depression and alcohol use disorders both independently predicted lower rates of self-reported school and/or work role functioning, and PTSD predicted deterioration in functioning in these roles as well. This finding mirrors the wider literature on PTSD and other psychiatric disorders and work role functioning discussed earlier. The symptoms of these disorders, which can involve fatigue, impaired concentration, loss of interest in activities, disrupted sleep, irritability, social withdrawal, vigilance, and behavioral avoidance, can all interfere with aspects of work attendance as well as effective relationships in the work setting. In addition, these disorders are associated with a wider range of social dysfunction, such as impaired interpersonal relationships [30-32], as well as physical complaints and problems [33-34] that could also negatively affect work or school role functioning. Thus, the finding that role functioning is lower for those with mental disorders is not surprising. The exception was the finding that subthreshhold PTSD was associated with better work role functioning when controlling for other types of pathology. We are reluctant to interpret this finding given that subthreshhold PTSD has been associated with impaired social functioning in the past [27]. It did not show a significant zero-order relationship with work role functioning, and a relatively small number of individuals were present with this diagnosis in the sample. We view this finding as likely arising because of multicollinearity among predictors in the model and sampling error.

In contrast to the findings on self-reported role functioning, we did not find that those diagnosed with mental disorders in this sample were less likely to be employed or in school. This finding echoes prior work suggesting that work role functioning is impaired rather than entirely eroded by psychiatric disorders [11-13,35]. It was also surprising to find that comorbidity (as assessed by the interaction analyses) did not demonstrate an effect on occupational functioning. Several factors may contribute to these findings. First, regarding the extent that these disorders and their comorbidity began postdeployment, they may be in early stages and may not have had time to erode social and occupational functioning to the point of participants quitting or being terminated from their jobs. Second, regarding employment status, substantial social pressures exist regarding employing returning veterans, our nation's newest generation of heroes, that could lessen the chance of them losing jobs even in the face of poorer performance. Third, it is possible that negative effects on job status are occurring on a more subtle level. Veterans with mental health diagnoses may, instead of losing their jobs, find that they attend less consistently, receive poorer job evaluations, are promoted less frequently as a result, and so forth. They may also be changing jobs frequently or be underemployed (working at levels beneath their capacity) because of their symptoms and difficulties. These important questions cannot be answered with the present data and require a more refined examination of occupational functioning and mental health diagnosis over time.

In any case, the finding that NGR servicemembers with mental health diagnoses are working or in school at equal rates to those without has some important implications. First, this represents relatively good news in that work is an important part of life that carries benefits beyond those that accompany a steady paycheck [36-39]. Work provides a potential focus, a social milieu, and in some cases, a useful distraction from troubling symptoms or problems. It should be noted, however, that while work is generally psychologically healthy and beneficial, stressful or difficult work situations, such as those that may be faced by individuals with chronic mental health difficulties, may carry their own cost [40-42]. These findings also suggest that employment services provided by the VA or other agencies for returning veterans need to address both obtaining employment or schooling and also functioning successfully within a work or school environment when mental health symptoms are present. Within the present sample at least, those with PTSD, depression, or alcohol use disorders are working and may need support or skills to maintain or excel in those work roles.

The present findings also highlight the importance of continuing to evaluate veteran occupational functioning over time. We surveyed the present sample relatively early during OIF, and repeated deployments, which are very 
common in today's military, can pose added difficulties for occupational functioning and mental health [43-44]. Further, the presence of occupational role impairments may have adverse effects on work role functioning and status over time, as noted earlier. Examining how veterans with mental health problems handle the challenges of the working world in the years to come will be important, both while OIF and OEF continue and once they have ended.

The conclusions and implications discussed here must be considered in light of the limitations inherent in the study design and sample. The present sample of NGR servicemembers, while one of the largest we are aware of reporting on structured clinical interviews and occupational functioning in OIF/OEF veterans, is relatively modest in size. Further, it is drawn entirely from one brigade combat team and as such may not represent mental health concerns, occupational functioning, or their interrelationship in other postdeployment contexts (e.g., AD servicemembers, servicemembers from other geographical regions). The limited sample size did not allow for consideration of other disorders that may be problematic but that were not present in sufficient numbers for analysis (such as other substance use problems). The present sample did not contain many servicemembers who had been seriously wounded during their service. Servicemembers who were most severely wounded may have been unlikely or unable to attend an outpatient clinical interview, though casualties for the overall brigade combat team were low for this deployment. Thus, our ability to evaluate the important role of physical disability on work role functioning in light of mental health distress is limited with this sample. While structured clinical interviews represent a gold standard for diagnostic classification, we assessed occupational functioning entirely by self-report and as such may be biased by either under- or overreporting of occupational difficulties. The current findings do not account for possible service-connection disability compensation, which could play a part in whether an individual who is both receiving such compensation and dealing with a mental health diagnosis is employed or in school. While this information would have been quite important if those with diagnoses were less likely to be working or in school, the lack of data on service-connection disability still represents a limitation to the present study. Finally, we collected the data during a period of economic decline. As such, changes between time points in overall employment may be attributable to multiple factors. For example, while we did not find an effect for mental health on employment status, it is possi- ble that the significant findings regarding the effects of mental health on individuals' work roles are caused by the economic downturn placing inordinately greater stress on individuals with mental health concerns. Future studies should incorporate multiple sources of information, including multiple informants and employment or academic records, to more fully assess this important dimension of functioning.

\section{CONCLUSIONS}

The findings reported here do require replication and extension in other military and veteran samples, but they also clearly point to a need for ongoing attention to, and support for, occupational functioning among servicemembers with mental health difficulties when they return from combat deployments. We found mental health diagnoses to be both common and associated with reduced role functioning in work and school in this sample of NGR servicemembers who had served in OIF. As OIF/ OEF continues and the potential for other military operations persists, attending to the broader levels of interpersonal and occupational functioning may serve as an important means of promoting the mental health and well-being of the large population of those who continue to serve the nation abroad.

\section{ACKNOWLEDGMENTS}

\section{Author Contributions:}

Study concept and design: C. R. Erbes, T. Schult, M. A. Polusny, P. A. Arbisi.

Analysis and interpretation of data: M. E. Kaler.

Drafting of manuscript: C. R. Erbes.

Critical revision of mansucritpt for important intellectual content:

C. R. Erbes, M. E. Kaler, T. Schult, M. A. Polusny, P. A. Arbisi.

Obtained funding: C. R. Erbes, M. A. Polusny, P. A. Arbisi.

Study supervision: C. R. Erbes, M. A. Polusny.

Financial Disclosures: The authors have declared that no competing interests exist.

Funding/Support: This material was based on work supported by the Minnesota Medical Foundation (grant 3662-9227-06), the Department of Defense Congressionally Directed Medical Research Program (grant W81XWH-07-2-003), the VA Health Services Research and Development program (grant RRP 08-385), and with resources and the use of facilities at the Minneapolis VA Health Care System. Institutional Review: All participants provided written informed consent to take part in study procedures. The Minneapolis VA Medical Center and University of Minnesota institutional review boards reviewed and approved the study protocols. 
Additional Contributions: Dr. Kaler is now with the Emily Program, St. Paul, Minnesota.

Participant Follow-Up: The authors plan to inform participants of the publication of the study via a recurring newsletter sent to all participants in the RINGS Cohort Study.

Disclaimer: The views expressed in this article are those of the authors and do not reflect the official policy or position of the VA, Department of the Army, or Department of Defense.

\section{REFERENCES}

1. Hoge CW, Castro CA, Messer SC, McGurk D, Cotting DI, Koffman RL. Combat duty in Iraq and Afghanistan, mental health problems, and barriers to care. N Engl J Med. 2004; 351(1):13-22. [PMID: 15229303] http://dx.doi.org/10.1056/NEJMoa040603

2. Hoge CW, Auchterlonie JL, Milliken CS. Mental health problems, use of mental health services, and attrition from military service after returning from deployment to Iraq or Afghanistan. JAMA. 2006;295(9):1023-32.

[PMID: 16507803]

http://dx.doi.org/10.1001/jama.295.9.1023

3. Smith TC, Ryan MA, Wingard DL, Slymen DJ, Sallis JF, Kritz-Silverstein D; Millennium Cohort Study Team. New onset and persistent symptoms of posttraumatic stress disorder self reported after deployment and combat exposures: Prospective population based US military cohort study. BMJ. 2008;336(7640):366-71. [PMID: 18198395] http://dx.doi.org/10.1136/bmj.39430.638241.AE

4. Iversen AC, Van Staden L, Hughes JH, Browne T, Hull L, Hall J, Greenberg N, Rona RJ, Hotopf M, Wessely S, Fear NT. The prevalence of common mental disorders and PTSD in the UK military: Using data from a clinical interviewbased study. BMC Psychiatry. 2009;9:68.

[PMID: 19878538] http://dx.doi.org/10.1186/1471-244X-9-68

5. Milliken CS, Auchterlonie JL, Hoge CW. Longitudinal assessment of mental health problems among active and reserve component soldiers returning from the Iraq war. JAMA. 2007;298(18):2141-48. [PMID: 18000197] http://dx.doi.org/10.1001/jama.298.18.2141

6. Seal KH, Metzler TJ, Gima KS, Bertenthal D, Maguen S, Marmar CR. Trends and risk factors for mental health diagnoses among Iraq and Afghanistan veterans using Department of Veterans Affairs health care, 2002-2008. Am J Public Health. 2009;99(9):1651-58. [PMID: 19608954]

7. Browne T, Hull L, Horn O, Jones M, Murphy D, Fear NT, Greenberg N, French C, Rona RJ, Wessely S, Hotopf M. Explanations for the increase in mental health problems in UK reserve forces who have served in Iraq. Br J Psychiatry. 2007;190:484-89. [PMID: 17541107] http://dx.doi.org/10.1192/bjp.bp.106.030544

8. Vogt DS, Samper RE, King DW, King LA, Martin JA. Deployment stressors and posttraumatic stress symptom- atology: Comparing active duty and national guard/reserve personnel from Gulf War I. J Trauma Stress. 2008;21(1): 66-74. [PMID: 18302185] http://dx.doi.org/10.1002/jts.20306

9. Savoca E, Rosenheck R. The civilian labor market experiences of Vietnam-era veterans: The influence of psychiatric disorders. J Ment Health Policy Econ. 2000;3(4):199-207. [PMID: 11967456] http://dx.doi.org/10.1002/mhp.102

10. Smith MW, Schnurr PP, Rosenheck RA. Employment outcomes and PTSD symptom severity. Ment Health Serv Res. 2005;7(2):89-101. [PMID: 15974155] http://dx.doi.org/10.1007/s11020-005-3780-2

11. Dewa CS, Lin E. Chronic physical illness, psychiatric disorder and disability in the workplace. Soc Sci Med. 2000; 51(1):41-50. [PMID: 10817467] http://dx.doi.org/10.1016/S0277-9536(99)00431-1

12. Lim D, Sanderson K, Andrews G. Lost productivity among full-time workers with mental disorders. J Ment Health Policy Econ. 2000;3(3):139-46. [PMID: 11967449] http://dx.doi.org/10.1002/mhp.93

13. Kessler RC, Frank RG. The impact of psychiatric disorders on work loss days. Psychol Med. 1997;27(4):861-73. [PMID: 9234464] http://dx.doi.org/10.1017/S0033291797004807

14. Munce SE, Stansfeld SA, Blackmore ER, Stewart DE. The role of depression and chronic pain conditions in absenteeism: Results from a national epidemiologic survey. J Occup Environ Med. 2007;49(11):1206-11. [PMID: 17993924] http://dx.doi.org/10.1097/JOM.0b013e318157f0ba

15. Kessler R, White LA, Birnbaum H, Qiu Y, Kidolezi Y, Mallett D, Swindle R. Comparative and interactive effects of depression relative to other health problems on work performance in the workforce of a large employer. J Occup Environ Med. 2008;50(7):809-16. [PMID: 18617837] http://dx.doi.org/10.1097/JOM.0b013e318169ccba

16. Polusny MA, Erbes CR, Murdoch M, Arbisi PA, Thuras P, Rath MB. Prospective risk factors for new onset PTSD in National Guard soldiers deployed to Iraq. Psychol Med. 2011;41(4):687-98. [PMID: 21144108] http://dx.doi.org/10.1017/S0033291710002047

17. Kehle SM, Reddy MK, Ferrier-Auerbach AG, Erbes CR, Arbisi PA, Polusny MA. Psychiatric diagnoses, comorbidity, and functioning in National Guard troops deployed to Iraq. J Psychiatr Res. 2011;45(11):126-32.

[PMID: 20541221] http://dx.doi.org/10.1016/j.jpsychires.2010.05.013

18. Weathers FW, Litz BT, Herman DS, Huska JA, Keane TM. The PTSD Checklist: Reliability, validity, and diagnostic utility. Proceedings of the Annual Meeting of the International Society for Traumatic Stress Studies; 1993 Oct; San Antonio, TX.

19. Blanchard EB, Jones-Alexander J, Buckley TC, Forneris CA. Psychometric properties of the PTSD Checklist (PCL). Behav Res Ther. 1996;34(8):669-73. [PMID: 8870294] http://dx.doi.org/10.1016/0005-7967(96)00033-2 
20. Beck AT, Steer RA, Brown GK. Manual for the Beck Depression Inventory-II. San Antonio (TX): Psychological Corporation; 1996.

21. Dozois DJ, Dobson KS, Ahnberg JL. A psychometric evaluation of the Beck Depression Inventory-II. Psychol Assess. 1998;10(2):83-89. http://dx.doi.org/10.1037/1040-3590.10.2.83

22. Babor TF, Higgins-Biddle JC, Sanuders J, Monteiro MG. AUDIT, the Alcohol Use Disorders Identification Test: Guidelines for use in primary care. 2nd ed. Geneva (Switzerland): World Health Organization; 2001.

23. Weissman MM. SAS-SR: Social Adjustment Scale-SelfReport. Toronto (Canada): MHS Inc; 1999.

24. King LA, King DW, Vogt DS, Knight J, Samper RE. Deployment Risk and Resilience Inventory: A collection of measures for studying deployment-related experiences of military personnel and veterans. Mil Psychol. 2006;18(2): 89-120. http://dx.doi.org/10.1207/s15327876mp1802 1

25. Blake DD, Weathers FW, Nagy LM, Kaloupek DG. The development of a clinician-administered PTSD scale. J Trauma Stress. 1995;8(1):75-90. [PMID: 7712061] http://dx.doi.org/10.1002/jts.2490080106

26. Weathers FW, Keane TM, Davidson JR. ClinicianAdministered PTSD Scale: A review of the first ten years of research. Depress Anxiety. 2001;13(3):132-56. [PMID: 11387733] http://dx.doi.org/10.1002/da.1029

27. Stein MB, Walker JR, Hazen AL, Forde DR. Full and partial posttraumatic stress disorder: Findings from a community survey. Am J Psychiatry. 1997;154(8):1114-19. [PMID: 9247398]

28. First MB, Spitzer RL, Gibbon M, Williams JB. Structured clinical interview for DSM-IV-TR axis I disorders, research version, non-patient edition. New York (NY): Biometrics Research, New York Sate Psychiatric Institute; 2007.

29. Kessler RC, Chiu WT, Demler O, Merikangas KR, Walters EE. Prevalence, severity, and comorbidity of 12-month DSM-IV disorders in the National Comorbidity Survey Replication. Arch Gen Psychiatry. 2005;62(6):617-27. [PMID: 15939839] http://dx.doi.org/10.1001/archpsyc.62.6.617

30. Monson CM, Taft CT, Fredman SJ. Military-related PTSD and intimate relationships: From description to theorydriven research and intervention development. Clin Psychol Rev. 2009;29(8):707-14. [PMID: 19781836] http://dx.doi.org/10.1016/j.cpr.2009.09.002

31. Tsing WS. Alcohol-related problems. In: Tseng WS, editor. Handbook of cultural psychiatry. San Diego (CA): Academic Press; 2001. p. 351-65. http://dx.doi.org/10.1016/B978-012701632-0/50093-0

32. Zlotnick C, Kohn R, Keitner G, Della Grotta SA. The relationship between quality of interpersonal relationships and major depressive disorder: Findings from the National Comorbidity Survey. J Affect Disord. 2000;59(3):205-15. [PMID: 10854637] http://dx.doi.org/10.1016/S0165-0327(99)00153-6

33. McDevitt-Murphy ME, Williams JL, Bracken KL, Fields JA, Monahan CJ, Murphy JG. PTSD symptoms, hazardous drinking, and health functioning among U.S. OEF and OIF veterans presenting to primary care. J Trauma Stress. 2010; 23(1):108-11. [PMID: 20104586]

34. Gaynes BN, Burns BJ, Tweed DL, Erickson P. Depression and health-related quality of life. J Nerv Ment Dis. 2002; 190(12):799-806. [PMID: 12486367] http://dx.doi.org/10.1097/00005053-200212000-00001

35. Stewart WF, Ricci JA, Chee E, Hahn SR, Morganstein D. Cost of lost productive work time among US workers with depression. JAMA. 2003;289(23):3135-44.

[PMID: 12813119]

http://dx.doi.org/10.1001/jama.289.23.3135

36. Blustein DL. The role of work in psychological health and well-being: A conceptual, historical, and public policy perspective. Am Psychol. 2008;63(4):228-40.

[PMID: 18473608]

http://dx.doi.org/10.1037/0003-066X.63.4.228

37. Kessler RC, Turner JB, House JS. Unemployment, reemployment, and emotional functioning in a community sample. Am Sociol Rev. 1989;54(4):648-57. http://dx.doi.org/10.2307/2095885

38. Lucas RE, Clark AE, Georgellis Y, Diener E. Unemployment alters the set point for life satisfaction. Psychol Sci. 2004;15(1):8-13. [PMID: 14717825] http://dx.doi.org/10.1111/j.0963-7214.2004.01501002.x

39. Vinokur AD, Schul Y, Vuori J, Price RH. Two years after a job loss: Long-term impact of the JOBS program on reemployment and mental health. J Occup Health Psychol. 2000;5(1):32-47. [PMID: 10658883] http://dx.doi.org/10.1037/1076-8998.5.1.32

40. Chen WQ, Siu OL, Lu JF, Cooper CL, Phillips DR. Work stress and depression: The direct and moderating effects of informal social support and coping. Stress Health. 2009; 25(5):431-43. http://dx.doi.org/10.1002/smi.1263

41. Kopp MS, Stauder A, Purebl GR, Janszky I, Skrabski, A. Work stress and mental health in a changing society. Eur J Public Health. 2008;18(3):238-44. [PMID: 17686795] http://dx.doi.org/10.1093/eurpub/ckm077

42. Wang JL, Lesage A, Schmitz N, Drapeau A. The relationship between work stress and mental disorders in men and women: Findings from a population-based study. J Epidemiol Community Health. 2008;62(1):42-47.

[PMID: 18079332] http://dx.doi.org/10.1136/jech.2006.050591

43. Office of the Surgeon Multi-National Corps-Iraq, Office of the Surgeon General. Mental Health Advisory Team 
(MHAT) VI: Operation Iraqi Freedom 07-09. Washington (DC): Department of Defense; 2009.

44. Polusny MA, Erbe CR, Arbisi PA, Thuras P, Kehle SM, Rath M, Courage C, Reddy MK, Duffy C. Impact of prior Operation Enduring Freedom/Operation Iraqi Freedom combat duty on mental health in a predeployment cohort of National Guard soldiers. Mil Med. 2009;174(4):353-57. [PMID: 19485103]

Submitted for publication November 4, 2010. Accepted in revised form April 22, 2011.
This article and any supplementary material should be cited as follows:

Erbes CR, Kaler ME, Schult T, Polusny MA, Arbisi PA. Mental health diagnosis and occupational functioning in National Guard/Reserve veterans returning from Iraq. J Rehabil Res Dev. 2011;48(10):1159-70.

DOI:10.1682/JRRD.2010.11.0212 